\title{
Differences in Psychopathology among Patients with Dual Diagnosis that are Entering Mental Health Services in Cyprus in Correlation with Alcohol Dependence
}

\author{
Maria $\mathrm{P}^{1 *}$, Alevizopoulos $\mathrm{G}^{2}$ and Tarabeih $\mathrm{M}^{3 *}$ \\ 1Department of Health Science, European University of Cyprus Nicosia, Cyprus \\ 2Department of Psychiatry, University of Athens, Greece \\ ${ }^{3}$ Tel Aviv-Jaffa Academic College, Israel
}

\section{Research Article}

Volume 2 Issue 5

Received Date: September 05, 2018

Published Date: September 21, 2018

*Corresponding author: Maria Prodromou, Department of Health Science, European University of Cyprus Nicosia, Cyprus, Email: M.prodromou@euc.ac.cy

\section{Abstract}

Introduction: Dual diagnosis is undoubtedly one of the most important problems that mental health services are currently facing. The common problem of all patients is that they resort to psychiatric services due to complications caused by the use or abuse of legal and illegal substances and at the same time due to the presence of another psychiatric disorder. The literature supports the hypothesis that psychiatric disorders and substance abuse disorders coexist more frequently than initially estimated.

Aim: The aim of this study is to examine, assess and compare the characteristics and the psychopathology between patients with dual diagnosis receiving treatment for mental disorders and those receiving treatment for substance abuse disorders within the framework of the substance abuse treatment programs provided by the Mental Health Services of Cyprus. Furthermore, this study examines the differences in psychopathology in correlation with alcohol dependence, duration of treatment and the number of hospitalizations in relation with dual diagnosis.

Methods: In this study three hundred patients were used: 150 of them were dually diagnosed and admitted to drug addiction therapeutic and rehabilitation centers for legal and illegal substances and 150 were dually diagnosed and admitted to psychiatric units in the Mental Health Center in Cyprus. The EuropASI the AUDIT, and the PDQ4 were administered individually to each participant. The Statistical Package for Social Sciences (SPSS) version 20.0 was used for data analysis.

Results: The results revealed that the dually diagnosed patients who were admitted to psychiatric units had higher figures of diagnosis (mhuM=3.03, duM=2.55, pvalue), higher figures of hospitalization in Mental Health Services ( $\mathrm{mhuM}=12.25$, duM=7.73) and significantly more psychological problems (mhuM=63.02, duM=18.78), as well as longer prison time (mhuM=5.55, duM=2.10), compared to those that entered substance abuse treatment programs. The mean 


\section{Nursing \& Healthcare International Journal}

age of first use for men was 17.88 for psychiatric patients and 17.52 for patients entering substance abuse treatment programs ( $\mathrm{p}$ value $=0.001$ ). For women, the mean starting age was 17.50 in psychiatric units and 17.60 in substance abuse treatment programs ( $p$ value=0.01).In most cases, the main substance of dependence was cannabis, followed by cocaine, in both study groups $(57.5 \%$ the case of cannabis, $20 \%$ for cocaine in psychiatric units and 30\% for cannabis, $20 \%$ for cocaine in substance abuse treatment programs). A total of $53.4 \%$ of the patients admitted to substance abuse treatment programs had a family history of alcoholism, while the corresponding figure for those in psychiatric units was $46.6 \%$; $50 \%$ of both groups had a family history of drug addiction. The patients with anti-social disorder according to the PDQ-4 questionnaire had a higher incidence of alcohol dependence than patients without anti-social disorder. The use of alcohol over the last 30 days was associated with an increase in the frequency of alcohol dependency.

Implications for Mental Health Nursing: The results indicate that the lack of a specialized treatment center creates a significant gap for treatment, which leads to Mental Health Services overuse and misuse, and to continuous hospitalizations and relapses, leading dual diagnosis patients to disorganization and isolation. Mental health specialists should learn and be educated in new therapeutic approaches in order to treat dually diagnosed patients holistically.

Keywords: Dual diagnosis; Drug addiction; Psychiatric unit; Drug addiction center; Treatment; Therapy; Psychiatric disorder

\section{Introduction}

The term "dual diagnosis" includes those individuals who experience drug addiction disorder and co-occurring psychiatric disorders. Reference is furthermore made to people with co-existing psychiatric disorders (Axis I or Axis II) and substance abuse disorders, as well as individuals who experienced both types of disorders during their lifetime, although not necessarily simultaneously [1-3].

Dual diagnosis may include any class of mental disorder that coexists with substance disorder, such as post-traumatic stress disorder, anxiety disorder, bipolar disorder, schizophrenia, mania, depression, and personality disorder. Usually, clinical characteristics are related to the type of psychiatric disorder that is presented by the individual. For example, numerous studies have highlighted the relationship between the presence of acute psychotic syndrome and mania and the use of cannabis. The various studies conducted on populations treated for substance abuse have indicated that around $50-75 \%$ of these individuals also presented some sort of mental disorder (without necessarily being a severe psychiatric disorder), while investigations into the populations treated for mental disorders recorded rates of $20-50 \%$ of coexisting substance abuse [4]. Various surveys have recorded similar rates of dual disorders in individuals entering drug-treatment regimens [5-11].

Consequently, the intense engagement of mental health specialists, researchers, and clinics in recent years with the issue of dual diagnosis is reasonable. It is now commonly accepted, both on the part of the Mental Health Services and the staff members, that there is a lack of evaluation and management of the issue and a lack of services for dually diagnosed patients, which lead to an increase in costs with ineffective service provision. Basically, significant improvements have to be made in order to enable Mental Health Services to provide a rich therapeutic environment to problems of dual diagnosis and the early treatment of consequent problems that affect both the individual as a unit and society as a whole. Within this framework, the need for research on this issue is important. The prospect of investigating dual diagnosis and the characteristics of people with dual diagnosis attempts to explain how this phenomenon affects the therapeutic effect, the course of the disease, the number of infections, and how it generally affects the use of mental health services [12-17]. 
The purpose of this research is to explore the characteristics of dually diagnosed patients who approach the Public Mental Health Services in Cyprus and examine the differences and similarities of the two groups: those that are entering substance abuse treatment programs and those entering psychiatric units in relation to demographic characteristics, the number of hospitalizations, the number of relapses and the frequency of coexistence of these two disorders. Additionally, other aims of this research are to explore the relation between the main substance abuse, the degree of alcohol dependence and the presence of specific mental disorders.

\section{Method}

Three hundred consecutive dually diagnosed patients took part in this study and are receiving treatment either for substance abuse disorders or for mental disorders in substance abuse treatment programs, emergency units, psychiatric hospitals and mental health rehabilitation units across Cyprus. They were grouped into two categories: mental health service patients $(n=150)$ and substance abuse treatment program patients $(n=150)$. Dual diagnosis treatment was not provided to any of the participants (Table 1).

\begin{tabular}{|c|c|c|c|}
\hline Characteristic & Psychiatric Unit & Drug Addiction Program & $\mathbf{P}$ \\
\hline Job situation & & & $<0,001^{\alpha}$ \\
\hline Full-time job & $8(19.0)$ & $34(81.0)$ & \\
\hline Part-time job & $3(18.8)$ & $13(81.3)$ & \\
\hline Unemployed & $132(60.3)$ & $87(39.7)$ & \\
\hline Students & $7(30.4)$ & $16(69.6)$ & \\
\hline Main source of income & & & $<0,001^{\alpha}$ \\
\hline Personal job & $10(19.6)$ & $41(80.4)$ & \\
\hline Social Insurance allowance/pension & $68(66.7)$ & $34(33.3)$ & \\
\hline Family/partner/friends & $47(52.8)$ & $42(47.2)$ & \\
\hline Illegal activity & $25(43.1)$ & $33(56.9)$ & \\
\hline
\end{tabular}

Table 1: Job and Economic Status of the Patients.

The questionnaires EuropASI, AUDIT, SCID and the PDQ-4 were administered individually to each one of the participants by the researcher. The researcher visited the units once a week in order to select and collect the sample over the course of 12 months (from 01/01/2014until01/01/2015).

In psychiatric units, those who had a positive effect on the urological substance detection test were evaluated and were present on the specific day of the visit. In substance abuse treatment programs, those who had a history of psychiatric disorder diagnosis based on the psychiatrist's assessment of the center, after crossing the history with the SCID (Structured Clinical Interview for DSM-IV Axis I Disorder) and PDQ-4 Diagnostic Questionnaire- version 4) were included in the sample. The sample of the study consisted of those who came to these services for duration of 12 months measured once in the specific period regardless of the time of entry. The study was explained in detail and informed consent was requested in order to proceed to the completion of the questionnaires.

\section{Inclusion and Exclusion Criteria}

The inclusion and exclusion criteria for the participants were as follows:

- Participant must be sober during the assessment.

- Participant must be able to provide data which meet the quality standards necessary for the data analysis processes.

- Participant must not be in a psychological state that puts them or other people in danger.

- Participant must not suffer from any brain damage or any cognitive or mental disorder due to a general medical condition.

- Participant must be over 18 and under 70 years of age.

\section{Instruments}

European Addiction Severity Index - Europ ASI [18]. The EuropASI is an adaption of the Addiction Severity Index - ASI 5th Edition [19] for the European population. The purpose of this instrument is to determine the severity of addiction to psychoactive substances. 


\section{Nursing \& Healthcare International Journal}

It is a semi-structured interview, containing 30 questions, mainly used for diagnostic purposes and assessment of the treatment outcome. The instrument consists of eight domains: general information, medical status, chemical use, employment/support, family/social relationships, legal status, and psychiatric/psychological status $[19,20]$.

The Europ ASI is considered a valid and reliable tool for assessing the severity of substance abuse in psychiatric populations. Test-retest reliability has been reported at 0.89 . It has been translated into Greek and also used in Cyprus by trained interviewers [21-24]. In this study, the first domain of the EuropASI (General Information) is used for the collection of information regarding the medical and legal history of the study participants.

AUDIT is considered a valuable, easy-to-use, fast, and reliable tool for investigating vulnerable populations and patients with severe co-morbidities of mental disorders and dependence. For these reasons, AUDIT is widely used in both primary prevention and inpatient patients for the early detection of alcohol abuse disorders [24-26].

The AUDIT questionnaire includes 10 questions, each rated from 0 to 4 . Out of a total of 10 questions, three concern alcohol use, four are about the addiction and three are about the problems caused by the use of alcohol. An overall rating of $\geq 8$ is indicative of a problem of alcohol abuse, with scores higher than 15 suggesting dependence, according to the manufacturer's instructions $[27,28]$. The translation of AUDIT into Greek from the English original was by two bilingual psychiatrists and by reverse translation. Studies have indicated that high internal affinity reliability (Cronbach a) was 0.78 for controls and 0.79 for patients. AUDIT has an increased internal affinity value and high validity with respect to clinical criteria, as well as high sensitivity and specialization.

\section{Bioethics and Ethics Issues}

The study relies on bioethical and ethical issues and it was necessary to observe the code of confidentiality and the patient's written consent for participation, as well as the appointment of a person to control the research process by the Committee for the Protection of Mental Patients. For these reasons, the Cyprus Bioethics Committee and the Commissioner for Personal Data Protection for the protection and safeguarding of patients' personal data, as well as the Research Committee of the Ministry of Health of Cyprus, have been asked for permission to conduct the study. Subsequently, once the aforementioned procedures had been completed, all the units under investigation were informed by the Director of the Mental Health Services about the authorization to conduct the study. Before participating in the study, participants signed a consent form. Anonymity and confidentiality were the basic principles of this study.

\section{Data Collection}

The Statistical Package for Social Sciences (SPSS) version 20.0 was used for data analysis. Descriptive statistics were used for demographic characteristics and a t-test was used to determine the differences in psychopathology between patients in mental health services and patients in substance abuse treatment programs. Furthermore, logistic regression analysis was conducted in order to determine the factors affecting psychopathology.

\section{Results}

The results revealed (Table 2) that the number of men entering substance abuse treatment programs was higher $(51.5 \%)$ in comparison with the number of men entering psychiatric units $(48.5 \%)$. The number of women that were entering psychiatric units was higher $(55.4 \%)$ than the number of women entering substance abuse treatment programs (44.6\%).

\begin{tabular}{|c|c|c|c|}
\hline Characteristics & $\begin{array}{c}\text { Psychiatric } \\
\text { Unit }\end{array}$ & $\begin{array}{c}\text { Drug Addiction } \\
\text { Center }\end{array}$ & Prize \\
\hline \multicolumn{3}{|c|}{ Sex } & $0.33^{\alpha}$ \\
\hline Male & $114(48.5)$ & $121(51.5)$ & \\
\hline Female & $36(55.4)$ & $29(44.6)$ & \\
\hline Age & $30.5 \pm 7.9$ & $31.7 \pm 10.0$ & $0.24 \gamma$ \\
\hline \multicolumn{3}{|c|}{ Marital status } & $0.02^{\alpha}$ \\
\hline Single & $8(29.6)$ & $19(70.4)$ & \\
\hline Divorced & $22(40.7)$ & $32(59.3)$ & \\
\hline Not married & $120(54.8)$ & $99(45.2)$ & \\
\hline
\end{tabular}




\section{Nursing \& Healthcare International Journal}

\begin{tabular}{|c|c|c|c|}
\hline \multicolumn{3}{|c|}{ Condition of living } & $0.02^{\alpha}$ \\
\hline With sexual partner and children & $26(68.4)$ & $12(31.6)$ & \\
\hline With sexual partner without children & $5(23.80)$ & $16(76.0)$ & \\
\hline Alone with children & $5(33.3)$ & $10(66.7)$ & \\
\hline With parents & $73(54.1)$ & $62(45.9)$ & \\
\hline With family & $19(40.4)$ & $28(59.6)$ & \\
\hline Alone & $22(50)$ & $22(50)$ & \\
\hline \multicolumn{3}{|c|}{ Area of living } & $<0.001^{\alpha}$ \\
\hline Nicosia & $42(31.8)$ & $90(68.2)$ & \\
\hline Limassol & $61(64.2)$ & $34(35.8)$ & \\
\hline Larnaca & $27(67.5)$ & $13(32.5)$ & \\
\hline Famagousta & $15(65.22)$ & $8(34.78)$ & \\
\hline Paphos & $4(50.0)$ & $4(50.0)$ & \\
\hline \multicolumn{3}{|c|}{ Level of education } & $0.33^{\delta}$ \\
\hline Primary school & $17(58.6)$ & $12(41.4)$ & \\
\hline Gymnasium & $51(58.0)$ & $37(42.0)$ & \\
\hline High school & $60(46.2)$ & $70(53.8)$ & \\
\hline University & $10(25.0)$ & $30(75.0)$ & \\
\hline Technical school & $7(87.5)$ & $1(12.5)$ & \\
\hline College & $5(100.0)$ & $0(0.0)$ & \\
\hline \multicolumn{3}{|c|}{ School dropout } & $0.04^{\alpha}$ \\
\hline No & $78(44.3)$ & $96(55.2)$ & \\
\hline Yes & $72(57.1)$ & $54(42.9)$ & \\
\hline Age & $13.3 \pm 1.5$ & $13.9 \pm 1.6$ & $0.02 \gamma$ \\
\hline
\end{tabular}

Table 2: Sociodemographic Characteristics of the Patients.

The patients in psychiatric units were single (54.8\%) as opposed to the patients that were entering the substance abuse treatment programs, where the majority of them were divorced (59.3\%). The majority of the patients who were entering the psychiatric units were living with their parents (54.1\%) in comparison with those who were entering substance abuse treatment programs that were less numerous (45.9\%) and predominantly living with a sexual partner without children $(76.20 \%)$.

According to their education level, the majority of the patients' entering the psychiatric units had dropped out of school (57.1\%) in comparison with those who were entering the substance abuse treatment programs $(42.9 \%)$. The age when they interrupted education was 13.3 years old for those entering psychiatric units and 13.9 years old for those entering substance abuse treatment programs.

According to their job status, the patients who were entering psychiatric units $(60.3 \%)$ were unemployed in comparison with those who were entering substance abuse treatment programs who were only $39.7 \%$ unemployed, with the majority of them having full-time jobs (81.0\%) in comparison with those entering psychiatric units who were only $19 \%$ with full-time jobs. The main source of income for the patients entering psychiatric units were the social insurance pensions $(66.7 \%)$ in comparison with the patients entering substance abuse treatment programs whose main source of income was primarily their personal job $(80.4 \%)$ in comparison with those entering psychiatric units (19.6\%).

According to the patients' family histories, $46.4 \%$ of drug addicts had a family history of alcohol abuse/drug abuse/psychiatric problem as opposed to $53.6 \%$ of those in psychiatric units. More specifically, those in psychiatric units had a greater family history of psychiatric problems $(71.4 \%)$ than those in substance abuse treatment programs $(28.6 \%)$. In addition, $53.4 \%$ of the drug addicts had a family history of alcoholism, while the corresponding figure for those in psychiatric units was $46.6 \% .50 \%$ of both groups had a family history of drug addiction. $72.7 \%$ of people with a family history of gambling addiction were in substance abuse treatment programs, while $27.3 \%$ of these individuals were in psychiatric units (Table 3). 


\begin{tabular}{|c|c|c|c|}
\hline Characteristics & Psychiatric Unit & $\begin{array}{c}\text { Drug Addiction Treatment } \\
\text { Centers }\end{array}$ & p value \\
\hline $\begin{array}{c}\text { Family History of Alcohol Abuse/Drug } \\
\text { Abuse/Psychiatric Problems }\end{array}$ & & & $0.27^{\alpha}$ \\
\hline No & $35(46.1)$ & $41(53.9)$ & \\
\hline Yes & $105(53.6)$ & $91(46.4)$ & \\
\hline Don't know & $10(35.7)$ & $18(64.3)$ & \\
\hline Family History of Psychiatric Problems & & & $<0.001^{\alpha}$ \\
\hline No & $85(40.7)$ & $124(59.3)$ & \\
\hline Yes & $65(71.4)$ & $26(28.6)$ & \\
\hline Family History of Alcoholism & & & $0.34^{\alpha}$ \\
\hline No & $95(52.2)$ & $87(47.8)$ & \\
\hline Yes & $55(46.6)$ & $63(53.4)$ & \\
\hline Drug Addiction Family History & & & $0.99^{\alpha}$ \\
\hline No & $125(50.0)$ & $125(50.0)$ & \\
\hline Yes & $25(50.0)$ & $25(50.0)$ & \\
\hline Family History of Gambling Addiction & & & $0.13^{\alpha}$ \\
\hline No & $147(50.9)$ & $142(49.1)$ & \\
\hline Yes & $3(27.3)$ & 8 (72.7) & \\
\hline
\end{tabular}

Table 3: Family History.

(Table 4) below shows the patient's score in the AUDIT questionnaire. For the majority of the sample, both groups (psychiatric unit and drug addicts) scored slightly differently in the AUDIT questionnaire. Specifically, 49.6\% of psychiatric patients had a score of 0-7 (physiological status), while the corresponding percentage for patients in substance abuse treatment programs was $50.4 \%$.
$51.9 \%$ of people in psychiatric units had a score of 8-15 (a problem), while the proportion of those in substance abuse treatment programs was $48.1 \%$. $49.6 \%$ of all patients in psychiatric units had a rating of $16-40$ (dependence), while the corresponding percentage for patients in substance abuse treatment programs was $50.4 \%$.

\begin{tabular}{|c|c|c|c|}
\hline Characteristics & Psychiatric Unit & $\begin{array}{c}\text { Drug Addiction } \\
\text { Treatment Center }\end{array}$ & P value \\
\hline Score in AUDIT questionnaire & & & 0.99 \\
\hline 0 till 7 (physiological status) & $57(49.6)$ & $58(50.4)$ & \\
\hline 8 till 15 (problematic use) & $28(51.9)$ & $26(48.1)$ & \\
\hline 16 till 40 (dependence) & $65(49.6)$ & $66(50.4)$ & \\
\hline
\end{tabular}

Table 4: Patient's Score in the AUDIT Questionnaire.

\section{Logistic Regression Analysis Results}

The association between the Type of Unit and the severity of the psychiatric disorder and the severity of dependence and treatment rates, were investigated by using the logistic regression analysis (Table 5). The results revealed that patients with severe psychiatric illnesses were more likely to enter a psychiatric unit than patients without severe psychiatric illnesses. The increase in the severity of dependence was associated with an increase in the frequency of admission to substance abuse treatment programs. The increase in treatment rates in a psychiatric hospital/clinic was associated with an increase in the frequency of admission to a psychiatric unit. The patients who enrolled following a court or a police order were enrolled to a greater extent in a psychiatric unit than patients enrolled without a court or a police mandate. 


\section{Nursing \& Healthcare International Journal}

\begin{tabular}{|c|c|c|c|}
\hline & Odds & 95\% 0dds & p value \\
\hline $\begin{array}{c}\text { Absence of severe psychiatric disorder in correlation with the } \\
\text { existence of severe psychiatric disorder }\end{array}$ & 5.57 & 1.51 post 20.53 & 0.01 \\
\hline Treatment rates in psychiatric hospital/clinic & 1.36 & 1.06 post 1.74 & 0.016 \\
\hline $\begin{array}{c}\text { Rates of admission without a court or a police mandate in } \\
\text { correlation with admission following court or police order }\end{array}$ & 0.007 & 0.002 post 0,03 & $<0.001$ \\
\hline
\end{tabular}

Table 5: Logistic Regression Analysis according to Type of Unit.

The variables account for $82 \%$ of the variability of admission to a substance abuse treatment program or psychiatric unit.

\section{Discussion}

The research regarding the differences between the two groups revealed that men had a higher representation in the sample (51.5\%) in substance abuse treatment programs as opposed to women with the highest number of those being admitted to psychiatric units (55.4\%). In a survey conducted at US psychiatric hospitals, where patient records were investigated for alcohol or illicit drug use during 2003-2007, it was found that the dual diagnosis rate was higher in women (54.6\%) than in men (38.4\%).In a research study by $\mathrm{Wu}$, et al. [10], it was revealed that patients with a dual diagnosis were more likely to be men. The group of patients enrolled in psychiatric units was more often single (54.8\%) with a large percentage living together with their parents (54.1\%), as opposed to the group of patients in substance abuse treatment programs where the largest proportion of patients were divorced (59.3\%). Similar results were also found in other investigations as in the Picci, et al. [13] study, where the participants were aged 18-44, single or divorced and widowed, and the same research by Rady, et al. [29] revealed that the majority of the sample $(63 \%)$ was single, with a low socio-economic and educational level. Additionally, the national survey by Magidson, et al. [30] indicated that people with double diagnosis were more likely to be divorced/deprived, in the absence of a supportive environment. The aforementioned finding may be related to the fact that in Cyprus, individuals with dual diagnosis are usually marginalized in the absence of a social life and cohabitation. At the same time, the beginning of substance abuse at a young age traps them in a permanent state characterized by a lack of maturation and emotional development and not assuming personal responsibility and establishing relationships (Table 6). This correlation needs further research in the future.

\begin{tabular}{|c|c|c|c|}
\hline & Odds ratio & $\mathbf{9 5 \%}$ Trust space & P value \\
\hline Age & 1.04 & 1.003 post 1,07 & 0.035 \\
\hline $\begin{array}{c}\text { Existence of antisocial personality disorder according to } \\
\text { questionnaire PDQ-4 in correlation with the absence of an } \\
\text { antisocial personality disorder }\end{array}$ & 2.33 & 1.30 post 4.14 & 0.004 \\
\hline $\begin{array}{c}\text { Use of alcohol during the last 30 days } \\
\text { y }\end{array}$ & 1.13 & 1.09 post 1.17 & $<0.001$ \\
\hline
\end{tabular}

Table 6: Multivariate Logistic Regression Analysis according to the degree of alcohol dependence by using the AUDIT questionnaire (score 0-7 = reporting category).

The majority of people in psychiatric units had a primary education at elementary school (58.6\%), and more often, they dropped out of school $(57.1 \%)$ at an average age of 13.3 years. The low level of education in this research is supported by other European studies where the presence of dual diagnosis was higher in patients with low socio-economic and educational backgrounds, usually with a total education of less than 9 years [29-34].
The majority of the sample included in the psychiatric unit was in the group of inactive subjects (60.3\%), with the main source of income being the pension or sickness benefit $(66.7 \%)$. This was in contrast to the patients admitted to substance abuse treatment programs where the majority acquired their main source of income illegally (56.9\%). The unemployment rates of the current survey are at the same level as the unemployment rates in the dual diagnosis populations in Europe, where dual diagnosis surveys often show instability in the place of

Maria P, et al. Differences in Psychopathology among Patients with Dual Diagnosis that are 


\section{Nursing \& Healthcare International Journal}

residence and high levels of unemployment [9,31,30,3537].

For the majority of the sample, both for psychiatric patients and for those in substance abuse drug addiction treatment centers, the AUDIT questionnaire score showed slight differences in all sub-scales. The results showed the use of alcohol (from 0 to 7), a slightly higher percentage of use among patients in psychiatric units (50.4\%); whereas as regards alcohol abuse (from 8 to 15), the percentages (51.9\%) and alcohol dependence (16 to 40 ) were slightly higher for the group of patients in substance abuse treatment programs (50.4\%). Several surveys that were conducted in the European area confirm the results of the association between abuse and alcohol dependence with the presence of dual diagnosis as in the case of Liang and Chikritzhs [38], who reported that patients with mood and anxiety disorders faced an increased risk of developing alcohol abuse or alcohol dependency compared to people without mental disorders. The risk of alcohol dependence was even higher for newly diagnosed patients (over 5 years of research) with mental disorders, especially when they were patients with bipolar disorder. In addition, this study demonstrated that the generalized anxiety disorder had a greater correlation with the risk of developing alcohol dependence, while social phobia and the posttraumatic stress disorder had a greater correlation with the risk of developing an alcohol abuse disorder. From the existing literature, it also appears that the use of alcohol for self-medication in patients with anxiety disorders is an important risk factor for the development of an alcohol dependence disorder.

The percentage of patients with dual diagnosis that were in psychiatric units and had a family history of alcohol/drug/psychiatric problems (53.6\%) was higher. More specifically, those in psychiatric units had a longer family history of psychiatric problems $(71.4 \%)$, while the percentage of people in the substance abuse treatment programs had a higher percentage of alcoholism in their family history (53.4\%); $50 \%$ of both groups had a family history of drug addiction, with a higher percentage of family history of gambling addiction for the patients entering the substance abuse treatment programs $(72.7 \%)$. The same results appear in the research of Gregg, et al. [39], concluding that the family history of substance abuse disorders can be considered to be a predictive factor for the coexistence of substance abuse disorders among schizophrenic patients. Other researchers support that the rate of parallel occurrence of alcoholism and dependence on psychoactive substances is particularly high. Percentages ranging from $30 \%$ to $51 \%$ of psychoactive substances add to alcohol dependence or are dependent on it, while the relatives of alcoholics often have problems related to the abuse of other substances or vice versa $[40,41]$.

Regarding the number of imports, small differences were found between the two groups of patients with those that were in psychiatric units having an average number of imports equal to 2 and respectively the group of patients that were in substance abuse treatment programs having an average number of imports equal to 1.7 during the year. Contrary to the number of imports during that year, people in substance abuse treatment programs had a higher average import (9.2) than those in psychiatric units (7.6). In addition, those in psychiatric units had a higher average number of hospitalizations for psychological/emotional problems (4.3) and a higher average (67.8 days) for treatment days for psychological problems as outpatients. Those results are supported from the findings of recent research, which indicate that drug use affects the number of relapses, hospitalizations, treatment time, and the possibility of completing the treatment of patients with double diagnosis $[2,10,12,13,17,42-44]$. More specifically, Zammit, et al. [42], through a systematic review of research, concluded that in people with psychotic disorders, the use of cannabis increases the incidence of recurrences and admissions for hospitalization while reducing the chances of completing treatment. Similar results came from the research by Batalla, et al. [12], which revealed that cannabis use and cocaine use increase the probability of re-admission for hospitalization among people experiencing psychotic episodes, especially during the first five years after the first psychotic episode.

The logistic regression analysis shows that the age was positively associated with the frequency of alcohol dependency. Older people had an increased frequency of alcohol dependence, possibly related to the fact that people who start using alcohol at an early age are then prone to alcohol abuse, and with the passage of time, dependence on alcohol. At the same time, people who show alcohol dependence are those who have been abusing alcohol for years and that alcohol dependence can last for years as the individual requests assistance at an advanced age.

Moreover, patients with antisocial personality disorder had a higher frequency of alcohol dependence. This finding that alcohol dependence is related to the presence of antisocial personality disorder is consistent with the findings of Torrens, Gilchrist, Domingo-Salvany 


\section{Nursing \& Healthcare International Journal}

and the psyCoBarcelona Group [45], who report that the majority of participants met the criteria for more dependence disorders during their lifetime and the most common dependency disorders observed were the dependence on heroin, cocaine, alcohol and sedatives. At the same time, $41.8 \%$ of participants experienced even a mental disturbance of Axis I during their lifetime, with mood disorders, anxiety disorders and antisocial or borderline/personality disorders being more frequent. Dual diagnosis patients who have been drinking alcohol for the past thirty days before entering Mental Health Services have also had an increased incidence of alcohol dependence with pvalue $<0.01$. The research by Ding, et al. [46] agrees with the above finding, arguing that the major drug use disorders in dual diagnosis patients who sought treatment in drug addiction treatment programs in US public hospitals were the withdrawal syndrome, withdrawal syndrome from illicit psychoactive substances, other chronic undetermined alcohol dependence disorders and chronic opioid dependence disorders. Alcohol appears to be one of the main substances of dependence among individuals with dual diagnosis [47-50].

\section{Conclusions}

The problem of dual diagnosis has become more common among Mental Health Services over the past few years, making it a top priority to provide appropriate treatment for both the clinical and the mental health policy makers. This phenomenon has also been strongly observed in Cyprus during the past fifteen years, with a great deal of concern for the clinicians regarding the way of treatment and clinical evaluation. For dual diagnosis treatment in Cyprus we have public and private substance abuse treatment programs. All cases entering those programs are upon request of the patient; only in public psychiatric units, such as in psychiatry hospitals, the patients are admitted involuntarily and under the pressure of the law. According to experts, at the clinical level, people with a dual diagnosis need treatment that is addressed in parallel to both coexisting disorders. The reality is that most of the services under investigation treat one disorder as a secondary one without setting therapeutic targets for the secondary disorder, resulting in frequent relapses due to a lack of proper treatment and management. So this creates the need for proper and extensive assessment of the dual diagnosis patients in the initial phase of treatment, while key types of treatment are psychosocial interventions, opioid substitution therapy, physical detoxification, treatment of psychopathology symptoms and co-treatment of both disorders in dual diagnosis treatment units.

This research is the first attempt to evaluate and investigate dual diagnosis in the Mental Health Services in Cyprus, setting the basis for further research efforts as well. Firstly, we identified the special characteristics of dual diagnosis patients who are approaching the investigated services as well as the usual mental disorders they present, the symptoms of psychopathology and in general, we made an attempt to outline the profile of dual diagnosis patients entering the Mental Health Services of Cyprus as well as its particular needs in terms of both personal, social, family, psychological, substance use history as well as dependence and web presence abuse. Subsequently, further investigation is needed on issues such as how the family environment affects the development of those individuals and their disorder as well as the investigation as to whether the treatment is related to the presence of dual diagnosis, whether the absence of a supportive environment exacerbates disturbance and increases their imports into these services, or whether or not medication is helping to treat the symptoms of psychopathology that these people are facing. The need to investigate the particular conditions of development of these individuals as well as the expression of their personal experiences in relation to the development of their disorder is something that will add to the clinical evaluation and treatment of these individuals. During this research, the patients have had the opportunity of active participation through focused interviews in which they expressed their own thoughts, opinions and feelings about the services provided and what they themselves consider as ancillary or not. This is all useful information for those that are involved in policymaking on the issue of addressing substance abuse and mental disorders in general, as it would be the trigger for creating treatment programs that respond to the specific needs of dual diagnosis patients.

Moreover, this research revealed the need for the implementation of a strategy that will strengthen the continuous care as well as communication between Mental Health Services in order to support mentally and physically dually diagnosed patients, give the right treatment and phase the problem of readmissions and minimize the problem of relapses. Patients entering compulsory psychiatric hospitals need to be subsequently linked to drug addiction programs in order to continue their treatment. 
A clear assessment framework with specific assessment tools, weighted, valid and reliable, will help to a large extent measure both the size of the problem and the appropriate treatment. Applying a clear single treatment policy with clear treatment contracts and a study of a unitary setting that will specialize in addressing individuals with dual diagnosis with distinct goals for both the patients themselves, their supportive system and the staff themselves, health and other stakeholders, would greatly contribute to a timely and immediate treatment as well as to reducing the cost of the services provided.

\section{References}

1. Lehman AF, Myers CP, Corty E (2000) Assessment and classification of patients with psychiatric and substance abuse syndromes. 1989. Psychiatr Serv 51(9): 1119-1125.

2. Lehmann S, Loh SH, Martins LM (2017) Enhancing NAD (+) salvage metabolism is neuroprotective in a PINK1 model of Parkinson's disease. Biol Open 6(2): 141-147.

3. Rassool GH (2006) Understanding dual diagnosis: An overview. In: Rassool GH (eds), Dual Diagnosis Nursing. Oxford: Blackwell Publishing Ltd, pp: 3-15.

4. Sacks S, Ries RK (2005) Substance abuse treatment for persons with co-occurring disorders. USA: Center for Substance Abuse Treatment.

5. Havassy BE, Alvidrez J, Owen KK (2004) Comparisons of patients with comorbid psychiatric and substance use disorders: implications for treatment and service delivery. American Journal of Psychiatry 161(1): 139145.

6. McGovern MP, Xie H, Segal SR, Siembab L, Drake RE (2006) Addiction treatment services and co-occurring disorders: Prevalence estimates, treatment practices, and barriers. J Subst Abuse Treat 31(3): 267-275.

7. Savant JD, Barry DT, Cutter CJ, Joy MT, Dinh A, et al. (2013) Prevalence of mood and substance use disorders among patients seeking primary care officebased buprenorphine/naloxone treatment. Drug and Alcohol Dependence 127(1): 243-247.

8. Vergara Moragues E, González Saiz F, Lozano OM, Betanzos Espinosa P, Fernández Calderón F (2012) Psychiatric comorbidity in cocaine users treated in therapeutic community: substance-induced versus independent disorders. Psychiatry Res. 200(2-3): 734-741.

9. Watkins KE, Hunter SB, Wenzel SL, Tu W, Paddock SM, et al. (2004) Prevalence and characteristics of clients with co-occurring disorders in outpatient substance abuse treatment. Am J Drug Alcohol Abuse 30(4): 749-764.

10. Wu LT, Gersing KR, Swartz MS, Burchett B, Li TK, et al. (2013) Using electronic health records data to assess comorbidities of substance use and psychiatric diagnoses and treatment settings among adults. J Psychiatr Res 47(4): 555-563.

11. Wu LT, Blazer DG (2015) Substance use disorders and co-morbidities among Asian Americans and Native Hawaiians/Pacific Islanders. Psychol Med 45(3): 481494.

12. Batalla A, Garcia Rizo C, Castellví P, Fernandez Egea E, Yücel M, et al. (2013) Screening for substance use disorders in first-episode psychosis: Implications for readmission. Schizophr Res 146(1): 125-131.

13. Picci RL, Versino E, Oliva F, Giaretto RM, Ostacoli L, et al. (2013) Does substance use disorder affect clinical expression in first-hospitalization patients with schizophrenia? Analysis of a prospective cohort. Psychiatry Res 210(3): 780-786.

14. Rady A, Salama H, Elkholy O, Shawky A (2013b) 792Dual diagnosis of mood disorders and substance abuse: the need for awareness. European Psychiatry 28: 1 .

15. Rady A, Salama H, Elkholy O, Shawky A (2013c) 793Dual diagnosis of personality disorders and substance abuse: the need for awareness. European Psychiatry 28: 1 .

16. Rady A, Salama H, Elkholy 0, Shawky A (2013d) 845Dual diagnosis of anxiety disorders and substance abuse: the need for awareness. European Psychiatry 28: 1.

17. van Dijk D, Koeter MW, Hijman R, Kahn RS, van den Brink W (2012) Effect of cannabis use on the course of schizophrenia in male patients: a prospective cohort study. Schizophrenia Research 137(1): 50-57.

18. Blacken P, Hendriks V, Pozzi G, Tempesta E, Hartgers C, et al. (1994) European Addiction Severity Index (EuropASI) $5^{\text {th }}($ edn), Athens: EMCCDA. 


\section{Nursing \& Healthcare International Journal}

19. McLellan AT, Kushner H, Metzger D, Peters R, Smith I, et al. (1992) The fifth edition of the Addiction Severity Index. J Subst Abuse Treat 9(3): 199-213.

20. Daughters SB, Magidson JF, Anand D, Seitz Brown CJ, Chen Y, et al. (2018) The effect of a behavioral activation treatment for substance use on posttreatment abstinence: a randomized controlled trial. Addiction 113(3): 535-544.

21. Kokkevi A, Hartgers C (1995) EuropASI: European adaptation of a multidimensional assessment instrument for drug and alcohol dependence. Eur Addict Res 1(4): 208-210.

22. Magidson JF, Stevenson A, Ng LC, Hock RS, Borba CP, et al. (2016) Massachusetts General Hospital Global Psychiatric Clinical Research Training Program: A New Fellowship in Global Mental Health. Acad Psychiatry 40(4): 695-697.

23. San L, Arranz B, Dual Pathology Clinical Practice Guide EG, Arrojo M, Becoña E, et al. (2016) Clinical guideline for the treatment of dual pathology in the adult population. Adicciones 28(1): 3-5.

24. Naimi TS, Stockwell T, Saitz R, Chikritzhs T (2017) Selection bias and relationships between alcohol consumption and mortality. Addiction 112(2): 220221.

25. Gache P, Michaud P, Landry U, Accietto C, Arfaoui S, et al. (2005) The Alcohol Use Disorders Identification Test (AUDIT) as a screening tool for excessive drinking in primary care: reliability and validity of a French version. Alcohol Clin Exp Res 29(11): 20012007.

26. Conigrave KM, Saunders JB, Reznik RB (1995) Predictive capacity of the AUDIT questionnaire for alcohol-related harm. Addiction 90(11): 1479-1485.

27. Saunders JB, Aasland OG, Babor TF, de la Fuente JR, Grant M (1993) Development of the alcohol use disorders identification test (AUDIT): WHO collaborative project on early detection of persons with harmful alcohol consumption--II. Addiction 88(6): 791-804.

28. WHO ( sredrosiD esU lohoclA eht :TIDUA (2001 htlaeh yramirp ni esu rof senilediug :tseT noitacifitnedI ,robaB F samohT ,erac2 .la tend (edn), World Health Organization, Geneva.
29. Rady A, Salama H, Elkholy O, Shawky A (2013a) 791Dual diagnosis of schizophrenia and substance abuse: the need for awareness. European Psychiatry 28(1).

30. Magidson JF, Liu SM, Lejuez CW, Blanco C (2012) Comparison of the course of substance use disorders among individuals with and without generalized anxiety disorder in a nationally representative sample. Journal of Psychiatric Research 46(5): 659666.

31. Maremmani AG, Dell'Osso L, Pacini M, Popovic D, Rovai L, et al. (2011) Dual diagnosis and chronology of illness in treatment-seeking Italian patients dependent on heroin. J Addict Dis 30(2): 123-135.

32. Bouvet L, Donnadieu S, Valdois S, Caron C, Dawson M, et al. (2014) Veridical mapping in savant abilities, absolute pitch, and synesthesia: an autism case study. Front Psychol 5: 106.

33. Bouvet L, Mottron L, Valdois S, Donnadieu S (2016) Auditory Stream Segregation in Autism Spectrum Disorder: Benefits and Downsides of Superior Perceptual Processes. J Autism Dev Disord 46(5): 1553-1561.

34. Tundo A, Necci R (2016) Cognitive-behavioural therapy for obsessive-compulsive disorder cooccurring with psychosis: Systematic review of evidence. World J Psychiatry 6(4): 449-455.

35. Dickey B, Normand SL, Weiss RD, Drake RE, Azeni H (2002) Medical morbidity, mental illness, and substance use disorders. Psychiatric Services 53(7): 861-867.

36. Watkins KE, Burnam A, Kung FY, Paddock S (2001) A national survey of care for persons with co-occurring mental and substance use disorders. Psychiatric Services 52(8): 1062-1068.

37. Ali B, Green KM, Daughters SB, Lejuez CW (2017) Distress tolerance interacts with circumstances, motivation, and readiness to predict substance abuse treatment retention. Addict Beht 73: 99-104.

38. Liang W, Chikritzhs T (2011) Affective disorders, anxiety disorders and the risk of alcohol dependence and misuse. The British Journal of Psychiatry 199: 219-224.

39. Gregg L, Barrowclough C, Haddock G (2007) Reasons for increased substance use in psychosis. Clinical Psychology Review 27(4): 494-510. 
40. Dinwiddie SH, Reich T, Cloninger CR (1991) The relationship of solvent use to other substance use. The American Journal of Drug and Alcohol Abuse 17(2): 173-186.

41. Mirin SM, Weiss RD, Griffin ML, Michael JL (1991) Psychopathology in drug abusers and their families. Compr Psychiatry 32(1): 36-51.

42. Zammit S, Moore TH, Lingford Hughes A, Barnes TR, Jones PB (2008) Effects of cannabis use on outcomes of psychotic disorders: systematic review. Br J Psychiatry 193(5): 357-363.

43. Magidson JF, Gouse H, Burnhams W, Wu CY, Myers B, et al. (2017) Beyond methamphetamine: Documenting the implementation of the Matrix model of substance use treatment for opioid users in a South African setting. Addict Behav 66: 132-137.

44. Tirado Muñoz J, Farré A, Mestre Pintó J, Szerman N, Torrens M (2018) Dual diagnosis in Depression: treatment recommendations. Adicciones 30(1): 6676.

45. Torrens M, Gilchrist G, Domingo Salvany A, psy Co Barcelona Group (2011) Psychiatric comorbidity in illicit drug users: substance-induced versus independent disorders. Drug Alcohol Depend 113(23): 147-156.

46. Ding K, Yang J, Cheng G, Schiltz T, Summers KM, Skinstad AH (2011) Hospitalizations and hospital charges for co-occurring substance use and mental disorders. Journal of Substance Abuse Treatment 40(4): 366-375.

47. McKeown O (2010) Definition, recognition and assessment. In: Philips $\mathrm{P}$, et al.

48. Ray O, Ksir C (1993) Drugs, society, \& human behavior. St. Louis: Mosby-Year Book.

49. Sandford (Eds), Dual diagnosis: Practice in context: Wiley-Blackwell, pp: 1-12, UK.

50. Naimi TS, Stockwell T, Zhao J, Xuan Z, Dangardt F (2017) Selection biases in observational studies affect associations between 'moderate' alcohol consumption and mortality. Addiction 112(2): 207214.

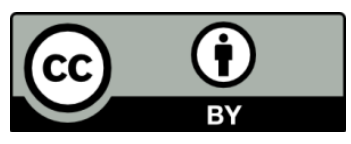

Maria P, et al. Differences in Psychopathology among Patients with Dual Diagnosis that are 